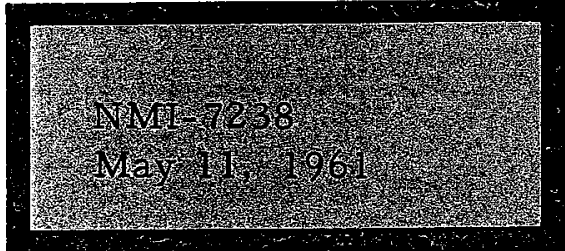

POWER REA OTOR PROARAM

PROGRESS R IPORT TO SA N NNAHRIVER

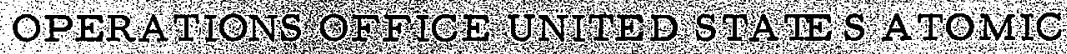
ENERGY COMMSSION FOR THE PERTOD MARGH 1, 1961,ITOUGH MARGH 31, 1961

S. Isserow, R, W, Anderson,W. J. R ichmond,

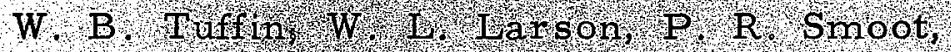
D. M. Davles. MU, Green and A. R. Glman

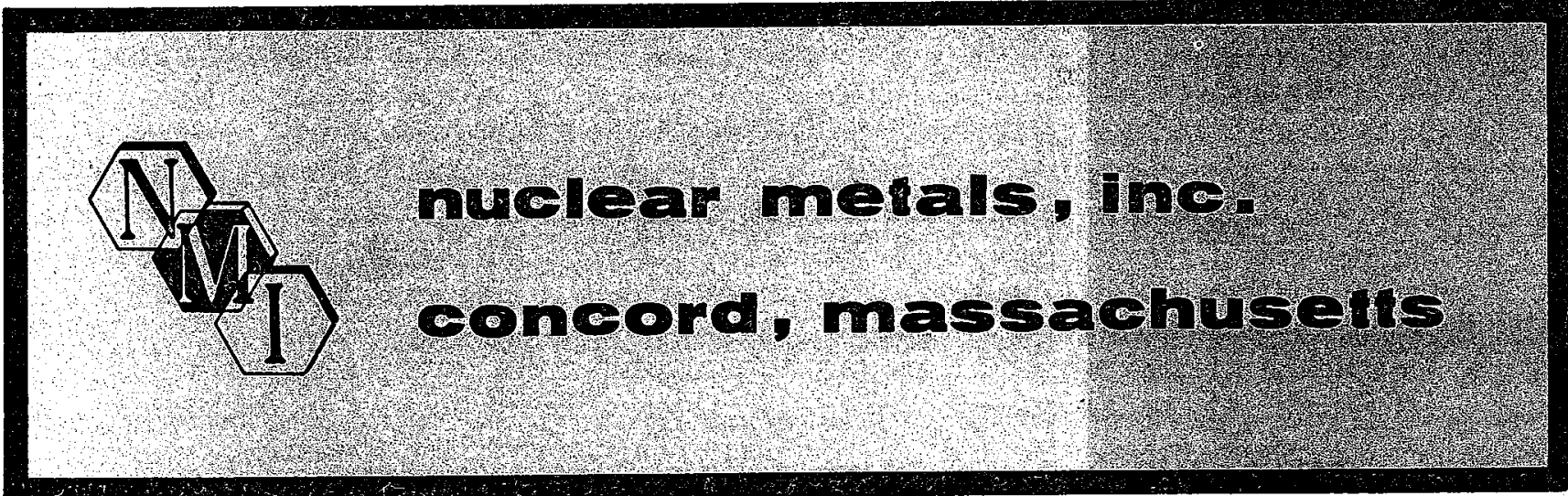




\section{LEGAL NOTICE}

This report was prepared as an account of Government sponsored work. Nelther the Unted States, nor the Commission, nor any person acting on behalf of the Commisaton:

A. Makes any warranty or representation, expressed or implied, with respect to the sccuracy, completeness, or usefulness of the information contained in this report, or that the use of any information, apparatus, method, or process disclosed in this report may not infringe privately owned rights; or

B. Assumes any liabilitles with respect to the use of, or for damages resulting from the use of any Information, apparatus, method, or process disclosed in this report.

As used in the above, "person acting on behalf of the Commisston" includes any employee or contractor of the Commission, or employee of such contractor, to the extent that such employee or contractor of the Commission, or employee of such contractor prepares, disseminates, or provides access to, any information pursuant to his employment or contract with the Commission, or hts employment with such contractor. 


\title{
Power Reactor Program
}

\author{
Progress Report to \\ Savannah River Operations Office \\ United States Atomic Energy Commission \\ for the Period
}

March 1, 1961 through March 31, 1961

S. Isserow, R. W. Anderson, W. J. Richmond

W. B. Tuffin, W. L. Larson, P. R. Smoot, D. M. Davies H. M. Green and A. R. Gilman

May 11,1961

Nuclear Metals, Inc.

Concord, Massachusetts

Contract No. AT(30-1)-1565

Sponsor Agreement No. S-31

A. R. Kaufmann

Technical Director 
Copy No:

External:

J. C. Woodhouse, du Pont, Wilmington 1-3

M. H. Wah1, du Pont, SRP 4-9

N. Stetson, AEC, SROO 10-12

R. C. Pugh, du Pont, Wilmington 13

\section{Internal:}

R. W. Anderson 14

L. R, Aronin 15

A. B. Bremer 16

T. H. Crim, Jr. 17

D. M. Davies 18

A. R. Gilman 19

H. M. Green 20

S. Isserow 21

E. F. Jordan 22

A. R. Kaufmann/W. B. Nowak 23

W. I. Larson 24

P. Loewenstein 25

W. J 。 Richmond 26

H. F. Sawyer 27

P. R. Smoot 28

W. B. Tuffin 29

Document Library 30-31

\section{SPECIAL DISTRIBUTION (pending patent release)}

\section{External:}

H. G. Hembree, USAEC, Chalk River, Canada 32-38

J. H. Rubin, USAEC, AECL, Canada $\quad 39$

E. C. Fiss, Carolinas-Virginia Nuclear Power Associates, Inc. 40 Angelo Giambusso, USAEC, Washington 41

A. T. Gifford, USAEC, Richland, Washington 42-45

H. V. Lichtenberger, General Nuclear Engineering Corporation 46

P. G. De Huff, WAPD

$47-48$

F.W. McCloska, Sargent and Lundy, Engineers 49

J. H. Hutton, Nuclear Development Corporation of America 50

D. R. Mash, Advanced Technology Labs. 51

OTIE, Oak Ridge, Tennessee $\quad$ 52-66 
Page No.

I. INTRODUCTION - S. Isserow

II. SUMMARY - R. W. Anderson 8

III. THIN-WALLED UNALLOYED TUBES 9

A. Improvement of Outer Tubes - W. J. Richmond 9

B. Modification of Beta Treatment for Coextruded Tubes - W. J. Richmond

C. Attempt to Eliminate Bowing by Autoclaving Under an Axial Load - W. B. Tuffin

D. Straightness of Inner Tubes - W. L. Larson

IV. EXPERIMENTAL CORE COMPOSITIONS

A. Specimens for Capsule Irradiation - P. R. Smoot, D. M. Davies and H. M. Green

B. Mechanical Behavior of Zircaloy-clad Uranium H. M. Green

V. DEVELOPMENT OF NEW FUEL MATERIALS - Cast Cores by Transient Melting - A. R. Gilman

VI. STAINLESS STEEL-ZIRCALOY JOINTS - W. B. Tuffin

VII. TABLES AND FIGURES 
Page No.

TABLE I - Minimum Cladding Thicknesses at Taper Sections of Tubes 122 and 123

TABLE II - Maximum and Minimum Cladding Thicknesses Over One Foot of the Center of Tubes 122 and 123

TABLE III - Summary of Outer and Inner cladding Thickness Variations Obtained from Optical Examination of Ring Sections from Tubes 122 and 123

TABLE IV - Shift, Eccentricity and Mandrel Bow in Extrusion of $\mathrm{Cu}-\mathrm{Ni}$ Cores in Zircaloy Sleeves

TABLE V - Influence of Different Beta Treatments on Grain Size Inferred from Compression Tests

TABLE VI - Mechanical Properties of Zircaloy-4-C1ad Dingot Uranium

FIGURE 1 - Modified extrusion billet with extended outer sleeve

FIGURE 2 - Load vs. deformation curves of Zircaloy-4-clad dingot uranium 


\section{INTRODUCTION - S. Is serow}

The program to develop components for heavy-water moderated reactors continued in March under Modification No. 17 of Agreement S-31 covering the period October 1, 1960, to September 30, 1961.

The evaluation of two outer thin-walled tubes showed that more uniform cladding had been achieved by more extensive working of the core stock. Experiments are being performed to overcome the remaining extrusion problems. The program to prepare specimens for capsule irradiation was completed.

The earlier reports for this program in the current contract period are numbered as follows:

$\begin{array}{ll}\text { For October } & \text { NMI-7233 } \\ \text { For November } & \text { NMI-7234 } \\ \text { For December } & \text { NMI-7235 } \\ \text { For January } & \text { NMI-7236 } \\ \text { For February } & \text { NMI-7237 }\end{array}$


II. SUMMARY - R. W. Anderson

Final evaluation of two thin-walled outer tubes has shown that more extensive alpha working of the billet core stock results in more uniform cladding on the extruded tube.

In an effort to eliminate breakthrough and to reduce eccentricity, shift, and bending of the mandrel, two experimental copper-nickel billets: with Zircaloy sleeves were extruded to check a modified billet design. The results indicate that breakthrough can be eliminated by using the modified design. Additional development is required to reduce the eccentricity, shift and bowing defects.

It has been observed that the final grain size of the unalloyed uranium core of a thin-walled outer tube is insensitive to small variations in the cooling rate from the beta treatment temperature.

An axial load of 3000 pounds applied to a thin-walled outer tube during autoclaving was ineffective in preventing bowing of the tube.

Shipping experiments have demonstrated that current packaging methods of thin-walled inner tubes do not prevent bowing during transit. A better method of packaging the flexible tubes for shipment is required.

The fabrication of specimens for the capsule irradiation program was concluded with the shipment of sixteen specimens and excess extruded tube stock to Savannah River Laboratory. The following core compositions were represented: $\mathrm{U}-1 \mathrm{~W} / \mathrm{o} \mathrm{Si}$, unalloyed dingot uranium, $\mathrm{U}-0.3 \mathrm{~W} / \mathrm{o} \mathrm{Al}$ $0.5 \mathrm{w} / \mathrm{o} \mathrm{Si}$, and $\mathrm{U}-0.3 \mathrm{~W} / \mathrm{o} \mathrm{Cr}-0.3 \mathrm{w} / 0 \mathrm{Mo}$. All irradiation specimens were supplied in the beta treated condition.

The mechanical behavior of Zircaloy-4-clad dingot uranium tube sections was evaluated as a function of the cooling rate from the beta treatment temperature. The results indicate that the mechanical behavior is approximately independent of the cooling rate and that, in testing to failure, fracture initiates within the core. Also, in a similar test of a transient melted ingot uranium tube, the uranium core appeared to be the most brittle component.

Five tubular stainless steel-Zircaloy joints were extruded for use in an experiment to determine if such joints can withstand 30 and 40 per cent cold reductions. 


\section{THIN-WALLED UNALLOYED TUBES}

\section{A. Improvement of Outer Tubes - W. J. Richmond}

\section{Introduction}

Two Zircaloy-clad uranium tubes (122 and 123) were extruded in February to determine whether more extensive alpha working of the core stock would make the outer cladding of the outer tubes as uniform as that of the inner tubes. In addition, changes in billet design and extrusion technique were incorporated in an attempt to minimize thinning of the front inner cladding and eccentricity. Evaluation of these two uranium tubes, and of one with a copper-nickel core extruded at the same time, was completed this month. Subsequently, modifications that prevent breakthrough have been demonstrated in two additional coppernickel extrusions, which also suggested other modifications to correct shift, eccentricity and mandrel bending.

\section{Post-Extrusion Evaluation of Tubes with Uranium Cores}

The preliminary examination last month of Tubes 122 and 123 revealed that on both tubes the $\mathrm{Z}$ ircaloy -4 broke through the copper extrusion jacket. It was also found that Tube 122 had less eccentricity and shift than Tube 123.

Further evaluation by autoradiography, summarized in Table $I$, shows that the cladding thickness at the end tapers of Tube $122^{\circ}$ is greater than the allowable minimum ( $21.5 \mathrm{mils}$ before removal of $1.5 \mathrm{mils}$ by etching) but the rear outer cladding of Tube 123 has a minimum of only $20.0 \mathrm{mils}$ before etching. The excessive shift of the tube is believed to have contributed to the thinning.

The center 1 -foot section of the uniform core of each tube was pickled and autoradiographed. The results in Table II show that the ranges of cladding thickness of both tubes are no greater than 4 mils over a foot of the uniform core.

Optical measurements of polished transverse ring sections of Tubes 122 and 123 were made and analyzed by the statistical procedure 
described in a previous report (NMI-7236, p. 13). Results are 1 isted in Table III. It may be noted that the sigma values of the outer cladding. of Tube 122 and of the inner cladding of both tubes are lower than the corresponding sigmas for inner tubes and previous outer tubes. It is evident that more extensive working of the core improved the cladding uniformity. The higher sigma values for Tube 123 are believed to be a manifestation of the greater shift and are not related to the chill casting of the core. Because of the shift, no conclusions can be drawn regarding any effect of chill casting.

Attention shifted to modification of the extrusion technique to overcome the problems of breakthrough, eccentricity, shift, and mandre1 bending.

\section{Modification of Extrusion Technique}

The problem of breakthrough encountered in the two uranium tubes did not appear in the copper-nickel tube extruded at the same time (see NMI-7237, p. 20). This absence of breakthrough in a billet with no zirconium end seals suggested a modification of the design for complete billets (sleeves and end seals) to simulate the situation in the coppernickel billet, where there was no stiff zirconium to force the front edge of the sleeve out. To check the usefulness of a material softer than zirconium in preventing breakthrough, the modified billet shown schematically in Fig. 1 has an extended outer sleeve into which the copper-nickel internal nose plug is inserted. The conventional copper nose was again used inside the billet since the high upset pressure of the external copper centering nose used for Tubes 122 and 123 may have contributed to the breakthrough.

Several changes were made in an attempt to minimize eccentricity. The effective bearing length of the mandrel backer at the time of billet upset was increased by shortening the die and cutoff, thereby permitting more of the backer to enter the liner, and by welding the scraper cone to the backer instead of shrinking it onto a recessed portion. In 
addition, the cutoff was shrunk onto the mandrel to hold the graphite centering ring (see Fig. 1) and the copper plate attached to the mandrel backer was increased from $1 / 16$ to $1 / 8$ inch in thickness.

Two modified complete billets with copper-nickel cores (to simulate uranium) in Zircaloy sleeves were extruded. No breakthrough occurred; apparently it can be eliminated by proper billet design. The shift, eccentricity and bowing that occurred are shown in Table IV. The three quantities appear to be interrelated. Thus, when the shift was small (No. 3), eccentricity of the tube and bowing of the mandrel were also small. Tube No. 4, which had the most shift, also was the most eccentric tube and the mandrel had a 4-mil bow after extrusion. Still further changes in the extrusion technique are required to reduce these quantities consistently.

\section{Proposed Extrusions}

Improved lubrication will be investigated for reduction of the shift. Two copper-nickel billets have been canned in copper for extrusion utilizing a lubrication technique developed at American Brass Company for copper-plated uranium billets. In this method all excess lubricant is wiped out of the liner. In addition, the temperature of the liner and all tools will be lowered to $700^{\circ} \mathrm{F}$. For these extrusions to check lubrication procedure, no Zircaloy sleeves will be used in the billets.

\section{B. Modification of Beta Treatment for Coextruded Tubes - W. J. Richmond}

Results of a preliminary investigation of the effect of the rate of cooling from the beta treating temperature on the grain size of thick- and thin-walled tubes were reported in NMI-7236 (p. 19). Grain size, inferred from the roughness of surfaces of samples subjected to compression by 20 per cent, became smaller as the cooling rate was increased. It appeared that additional work was warranted to permit specification of the optimum method for cooling full-size tubes. This work was planned in three stages, starting with 3 -inch specimens to bracket 
the optimum conditions and then proceeding to longer specimens and, finally, to full-length tubes. Results reported here on 3-inch long specimens indicate that refinement of grain size of an outer thinwalled tube has not been achieved by the slight increases in cooling rate over that provided by the usual air cooling.

Seven 3 -inch long sections of Tube 74B were cooled under various conditions from the beta treating temperature. Samples were cooled in still air or in oil to determine the effects of relatively slow and fast cooling rates. Intermediate rates were obtained by cooling in salt at $970^{\circ} \mathrm{F}$ or in forced air. For forced air cooling, samples were held in a 5-inch diameter vertical pipe through which air was moved by a blower and controlled by an intake gate. The low air temperatures in some tests were obtained by drawing air through a 2 -inch vertical layer of Dry Ice.

The results of the compression test, summarized in Table $\mathrm{V}$, show that cooling obtained in forced air or in salt at $970^{\circ} \mathrm{F}$ gives a grain size barely distinguishable from that obtained in still air and indistinguishable from each other. Since there is a possibility that the compression test may not be sensitive enough to detect small grain size differences, metallographic examinations were made to seek any differences not detectable in the compression tests. Examination of $3 \mathrm{X}$ photomacrographs of transverse sections confirmed the results of the compression test: the grain size of the samples cooled in forced air or salt appears very similar to that in samples cooled in still air. No further work is planned on modification of cooling rates.

C. Attempt to E1 iminate Bowing by Autoclaving Under an Axial Load - W. B. Tuffin

Processing of the demonstration set of six outer thin-walled tubes showed (see NMI-7234, p. 10) that tubes cold straightened after beta treatment bow during autoclaving, with the bows returning in the same angular location to about half their original magnitude. The postautoclaving bows have been as great as $1 / 2$ inch whereas a maximum of 
$1 / 8$ inch is specified. Straightening after autoclaving is not desirable, because of the possibility of inflicting undetected damage to the cladding and, in addition, such bows might return during in-pile use. Consequently, an attempt was made to avoid bowing by autoclaving under a high axial load.

A spring-loaded device was assembled for use in the 18-foot autoclave. This device can exert an axial load of about 3,000 1bs. which, for thinwalled outer tubes, represents a stress of about 3,000 psi on the wall. The load is applied during the entire time that a tube is in the autoclave. The tube used for the experiment (No. 112) had a bow of about 1 inch after beta treatment. It was then cold straightened, but a bow of about $1 / 2$ inch returned at the same angular position during the initial autoclaving. The tube was restraightened to within $1 / 64 \mathrm{inch}$, loaded in the autoclave with the spring-loaded device, and subjected to a 24 -hour $/ 650^{\circ} \mathrm{F}$ water plus 24-hour $/ 750^{\circ} \mathrm{F}$ steam (1500 psi) autoclave cycle. Subsequent examination of the tube showed that a 1/4-inch bow had returned at the same position as the prior bow. Since this $1 / 4$-inch bow again represented a return of about one half the bow before autoclaving, it was concluded that an axial load of 3,000 1bs. during full-scale autoclaving is ineffective in preventing bowing in thin-walled outer tubes. Larger loads during autoclaving may be effective, but they are not obtainable with present equipment.

\section{Straightness of Inner Tubes - W. L. Larson}

In January, Tubes 117 and 119, two of a demonstration set of six tubes, were shipped to the Savannah River Laboratory as irradiation candidates. It was recently reported to NMI that the bow measurements obtained at SRL for these tubes were not in agreement with those obtained by NMI before shipment and previously reported in NMI-7236. The maximum bows measured at NMI for Tubes 117 and 119 were 0.140 inch and 0.180 inch, respectively; the corresponding measurements made at SRL for these tubes were 0.200 inch and 0.250 inch, respectively, or about 40 per cent greater than the values obtained at NMI. The difference in the measurements could be due to differences in the technique of measuring bow at the two locations and/or deformation of the tubes during packaging, handling, and 
transporting to SRL. More recently it has been established that the methods of measurement at the two sites are basically similar.

In an effort to determine the reason for the difference, a handling experiment was carried out using Tube 118 from the demonstration set. This tube has been processed through etching but has not been autoclaved. After being etched, Tube 118 remained in a storage rack at NMI for more than two months. Measurements before and after this storage period indicated a maximum bow of 0.080 inch at a $90^{\circ}$ angular location, 6 feet from the front of the tube. These measurements indicated that the handling did not introduce any. bow:

During a one-day handling test, Tube 118 was packed by the usual procedure (in cardboard tube, steel pipe, and wooden box), and transported by the truck for one short trip ( 2 miles). After being unpacked and inspected, it was found that the maximum bow of the tube remained essentially unchanged.

During a subsequent handling test, the packaged tube was on the truck for 6 days and was transported 200 miles before being unpacked and inspected. The maximum bow of the tube was increased by 20 per cent to 0.100 inch, due to the transporting operation.

It appears that the different bows measured at NMI and SRL for Tubes 117 and 119 are due to effects of transportation rather than to any differences in the methods of measurement. A better method of packaging the flexible inner tubes is necessary to insure against the possibility of additional deformation of these tubes during transit between NMI and SRL. 
IV. EXPERIMENTAL CORE COMPOSITIONS

A. Specimens for Capsule Irradiation - P. R. Smoot, D. M. Davies and H. M. Green

The fabrication of specimens for the capsule irradiation program was concluded with the shipment of sixteen specimens and excess extruded tube stock to Savannah River Laboratory. Each core composition is discussed individually below.

\section{1. $\mathrm{U}-1^{\mathrm{W}} / \mathrm{O}$ Si Specimens}

The second ends of the three beta treated U- 1 w $/ 0 \mathrm{Si}$ specimens were brazed, Dy-Chek evaluated and found acceptable.

\section{Unalloyed Dingot Uranium Specimens}

A total of eight dingot specimens has been prepared, four with welded end closures and four with brazed end closures. Seven specimens met all specifications. The eighth, a brazed specimen containing a thermowell at one end, deviated from specifications as a result of closure of the thermowell hole during brazing. Radiography of the defective specimen indicated that the thermowell was clear $1 / 8$ inch below the end cap surface. The thermowell can be cleared either by drilling or by facing off the end cap.

\section{3. $\mathrm{U}-0.3^{\mathrm{W}} / 0 \mathrm{Al}-0.5^{\mathrm{W}} / \mathrm{O} \mathrm{Si}$ Specimens}

Four specimens with $\mathrm{U}-0.3 \mathrm{~W} / \mathrm{o} \mathrm{Al}-0.5 \mathrm{w} / \mathrm{o} \mathrm{Si}$ cores were provided with welded end closures and beta treated. The specimens were taken from an experimental extrusion that was intended to establish the extrusion constant and tool dimensions (see NMI-7236, p. 25; the extrusion constant at $1200^{\circ} \mathrm{F}$ was 21 tons per square inch). The specimens met al1 specifications except for a slight deviation of the outside diameter.

As stated in the February report, studies were to be conducted to determine whether the higher strength of the gamma quenched material 
$\left(1470^{\circ} \mathrm{F}, 10\right.$ minutes, oil quenched) might be due to the retention of the beta phase. X-ray diffraction analysis of the gamma quenched material revealed that the structure of the core consisted of beta phase uranium plus intermetallic compounds. Since this alloy composition was selected to evaluate the irradiation characteristics of alpha uranium with a fine dispersion, the capsule specimens were supplied in the beta treated condition.

\section{4. $\mathrm{U}-0.3^{\mathrm{w}} / 0 \mathrm{Cr}-0.3^{\mathrm{w}} / 0$ Mo Tube}

As reported last month, the experimental casting UX-524 was held at $600^{\circ} \mathrm{C}\left(1110^{\circ} \mathrm{F}\right)$ for 2 hours during the cooling cycle to permit the beta to alpha transformation. Metallographic and Dy-Chek inspection of the ingot revealed cracks in the upper 6 inches of the 10inch casting. The size and density of cracks decreased from top to bottom and no cracks were observed in the bottom four inches. Chemical composition of the ingot was found to be as follows:

$\begin{array}{lllll} & \text { Carbon } & \text { Chromium } & \text { Molybdenum } & \text { Iron } \\ \text { Top } & 490 \mathrm{ppm} & 0.281 \mathrm{w} / 0 & 0.31 \mathrm{w} / \mathrm{o} & 121 \mathrm{ppm} \\ \text { Bottom } & 315 \mathrm{ppm} & 0.298 \mathrm{w} / 0 & 0.31 \mathrm{w} / 0 & 317 \mathrm{ppm}\end{array}$

The ingot was coextruded at a reduction ratio of $14: 1$ at $1100^{\circ} \mathrm{F}$. The extrusion constant was 24.5 tons per square inch. The tube had excellent surfaces. It was shipped to SRL for further evaluation for possible use for capsule specimens.

Metallographic and X-ray diffraction studies of the core in the asextruded condition were made on samples from the front and rear of the coextruded tube. Examination of a transverse plane indicated an average grain size of about 5 microns. No cracks were observed in a longitudinal plane at $250 \mathrm{X}$ in specimens from either end of the tube. In a transverse plane, however, fine seams were observed in the specimen from the rear of the tube. These seams may be the end of an extrusion defect rather than 
the remnants of cracks in the casting. The core-cladding interfaces were fairly smooth and the structure (except for the seam-type defects) was similar at both ends.

$X$-ray diffraction studies revealed that the core consisted entirely of beta phase uranium. The degree of preferred orientation was observed to be the same at the front and rear of the tube.

\section{B. Mechanica1 Behavior of Zircaloy-clad Uranium - H. M. Green}

The mechanical properties were determined for Zircaloy-4-clad dingot uranium in different conditions. The specimens were obtained from a coextruded tube used for capsule specimens (NMI-7235, p. 16). Two-inch long sections cut from the uniform core region of the tube were beta treated at $1350^{\circ} \mathrm{F}$ for 10 minutes and cooled in three different ways. One piece was air cooled to room temperature, the second was oil quenched, and the third was quenched to $960^{\circ} \mathrm{F}$, held for one minute and then air cooled to room temperature (interrupted quench). The room-temperature mechanical properties were evaluated by free bend (see figure with Table XII of NMI-7237), diametral compression (using full rings) and hardness tests. The free bend and diametral compression tests were performed at a constant deformation rate of $0.2 \mathrm{in.} / \mathrm{min}$. and $10 a d-t i m e$ curves were autographically obtained. Material in the as-extruded condition was also evaluated for comparison of the diametral compression and free bend tests. Metallographic examinations were conducted of transverse faces of specimens in each of the four conditions prior to and after testing.

\section{Mechanical Properties}

The test results are presented in Table VI and Fig. 2. The loads required to deform the specimens 0.040 inch were determined from the load-deformation curves of the respective specimens. To correct for differences in specimen dimensions, the expression for elastic bending in uniform beams $\left(S=\frac{M C}{I}\right)$ was applied. Even though the results reported in Table VI are in units of stress (psi), they are intended to be considered only as dimensionally normalized values. The ductility parameter 
reported in Table VI was obtained by dividing the amount of deformation at fracture $\Delta \mathrm{h}$ (determined from the load-deformation curves) by the initial distance $h_{0}$ between the loading points.

The relative strengths from both the free bend and diametral compression tests are consistent with the respective hardness data. As a result of the brittle behavior of specimens in the extruded condition, the diametral compression test specimens fractured under the loading points at the inner cladding-core interface at relatively small deformations. Consequently, the ductility appears less when evaluated by the diametral compression test than when evaluated by the free bend test. One of the two as-extruded diametral compression specimens was deformed further until a second fracture occurred $90^{\circ}$ from the loading points. The minimum radius of curvature of this specimen was similar to that noted for the free bend test specimens. Thus, when properly evaluated, both tests yield similar results for brittle as well as ductile materials.

The load-deformation curves and the room-temperature hardness results indicate that the strength of Zircaloy-clad dingot uranium is relatively independent of the cooling rate from the beta-treatment temperature. The ductility after the interrupted-quench is somewhat superior to that after the other two methods of cooling from the beta temperature.

\section{Metallographic Examination}

Metallographic examination revealed that the core of all the beta-treated specimens contained relatively large irregularly shaped grains. The grain size of the core of the oil-quenched specimen was smaller than in either the air-cooled or interrupted quenched specimens. The thickness (about $0.5 \mathrm{mils}$ ) and structure of the diffusion zone appeared to be independent of the cooling rate.

Metallographic examination after testing indicated that the fracture propagated intergranularly within the core for all conditions but the interrupted quench. In the latter condition, the path of the fracture could 
not be definitely established. With all cooling rates, radial cracks were noted in the diffusion zone on either side of the main fracture; the number of cracks appeared to decrease with decreasing cooling rate. Even though cracks were noted in the diffusion zone, they did not appear to propagate. Hence, it is believed that cracks in the core are responsible for fracture. 


\section{DEVELOPMENT OF NEW FUEL MATERIALS - Cast Cores by Transient}

\section{Melting - A. R. Gilman}

In the program to evaluate the applicability of transient zone melting to produce a cast structure in the core of clad, coextruded fuel tubes, additional determinations of uranium core texture after melting are in progress, and a bend test was made to evaluate the properties of the core-cladding interface. Specimens were taken from the transientmelted portion of the thin-walled outer tube No. 85 (NMI-7236, p. 31).

\section{A. Texture Measurements}

The determination of the radial growth index (G-3) is required for assessing the advisability of irradiating cast cores produced by transient melting. The outer cladding was machined away from a oneinch long specimen, and the machined surface was etched to reveal the macroscopic uranium grain pattern. Since there was no significant variation in grain pattern around the circumference of the tube section, it appeared that specimens can be cut for growth index measurements with good confidence that representative values will be obtained.

\section{B. Bend Tests}

A one-half inch wide ring was diametrally compressed until it fractured across the tube wall. A force of 1350 pounds had reduced the diameter by $0.4 \mathrm{inch}$. By metallographic examination a short radial crack was found in the uranium core near the inner cladding diametrically opposite the fracture point (a region subjected to the same force as the fractured area), and this crack had not propagated into the interface layer or the cladding. Since no radial cracks were found at any point in the interface layer, the layer is presumed to be more ductile than the core. The Zircaloy cladding in the region of the fracture was reduced in thickness, demonstrating its expected ductile behavior. Thus, the uranium core appears to be the most brittle component of the tube. No circumferential cracking was observed. 
VI. STAINLESS STEEL-ZIRCALOY JOINTS - W. B. Tuffin

The amenability of extruded stainless steel-Zircaloy joints to cold reductions of up to 20 per cent by the Tube Reducing process has been demonstrated. (See NMI-7237.) Although cold reductions in excess of 20 per cent are reported to have no additional strengthening effect on the $Z$ ircaloy, an experiment will be carried out to determine whether joints can withstand cold reductions of 30 and 40 per cent. A favorable result will give confidence that cold reductions of 20 per cent are not borderline and will permit greater latitude in fabrication.

Five 2-inch diameter joints were extruded to provide tubes for this cold working experiment. Procedures followed previously in preparing joints for cold working have been modified. The five joints, which had as-extruded bows of up to 0.125 inch, were cold straightened with the mild steel extrusion jacket in place. Joints were then submitted directly to machining, thus eliminating the pickling step. Machining procedures were modified to attempt to eliminate the bowing which occurred during the machining of previous sets of joints. For this set of joints the inside surfaces were first machined, thus leaving the stronger layer of metal on the outside to withstand any residual stresses resulting from the cold straightening. Close-fitting graphite mandrels were then inserted inside the joints for support during the machining of the outside surface. Two tubes handled in this manner have been machined concentrically. Machining of the other joints is in progress and it is expected that the cold working experiment will be performed in April. 
TABLE I

Minimum Cladding Thicknesses* at

Taper Sections of Tubes 122 and 123 (mils)

Tube $122 \quad$ Tube 123

$\begin{array}{llll}\text { Front } & \text { Inside } & 23.0 & 22.5 \\ & \text { Outside } & 26.0 & 24.5 \\ \text { Rear } & \text { Inside } & 26.5 & 26.5 \\ & \text { Outside } & 25.0 & 20.0\end{array}$

* Before removing 1.5 mils by etching.

TABLE II

Maximum and Minimum Cladding Thicknesses* Over

One Foot of the Center of Tubes 122 and 123 (mils)

$\begin{array}{lccc} & & \text { Tube } 122 & \text { Tube } 123 \\ & & 30.0 & 27.0 \\ \text { Inner Cladding . Max } & 26.0 & 25.0 \\ & \text { Min } & 27.0 & 27.5 \\ \text { Outer Cladding } & \text { Max } & 25.0 & 23.5 \\ & \text { Min } & & \\ \text { * Before removing } 1.5 \text { mils by etching. }\end{array}$




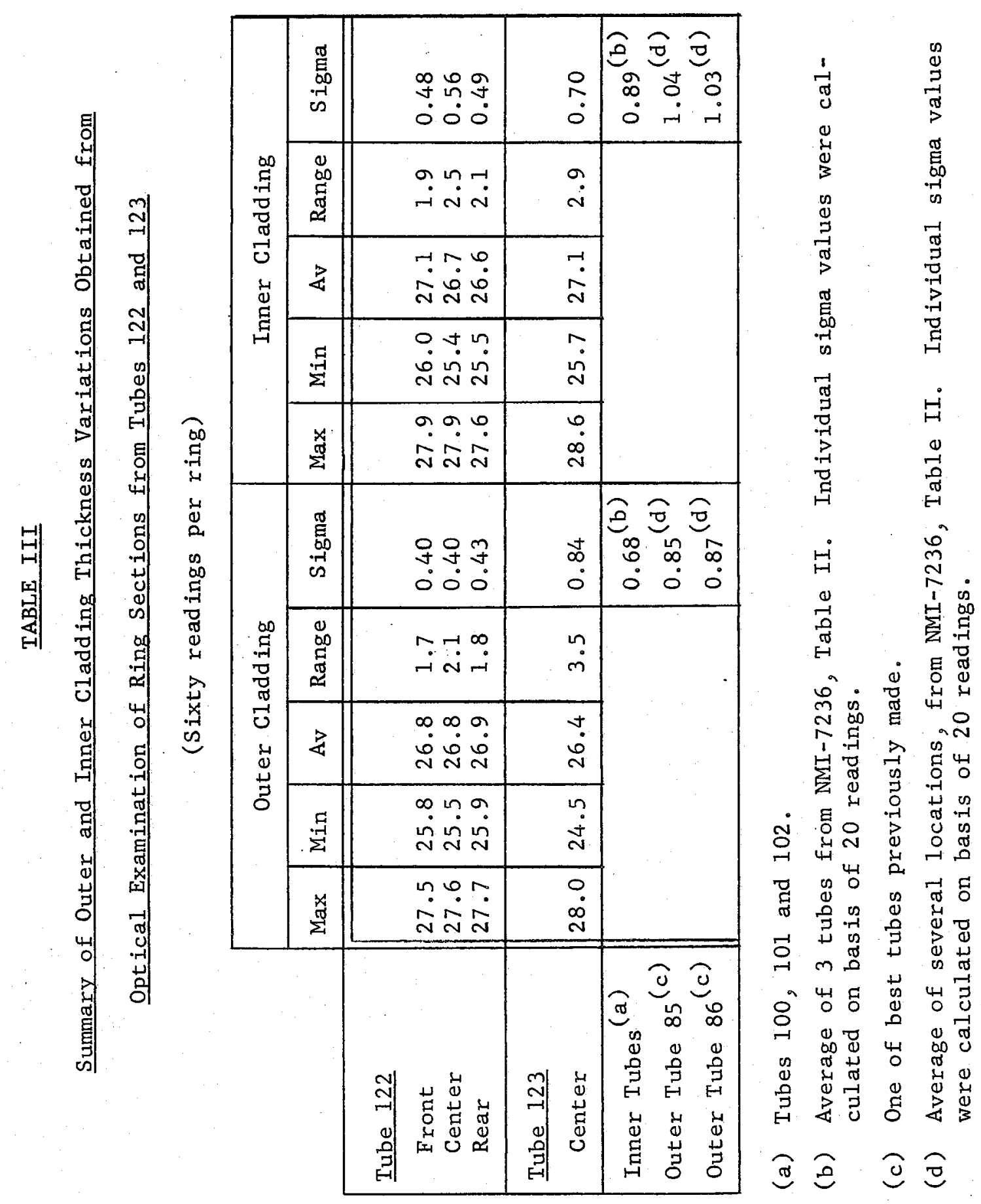




\section{TABLE IV}

Shift, Eccentricity and Mandrel Bow

in Extrusion of $\mathrm{Cu}-\mathrm{Ni}$ Cores in Zircaloy Sleeves

$\begin{array}{lcc} & \text { No. } 3 & \text { No. } 4 \\ \text { Shift (inches) } & 0.5 & 1 \\ \text { Eccentricity (mils) } & & \\ \quad \text { Front } & 2 & 2 \\ \text { Center } & 4 & 12 \\ \quad \text { Rear } & 4 & 12 \\ \text { Mandrel Bow (mils) } & 1 & 4\end{array}$


TABLE V

Influence of Different Beta Treatments ${ }^{(1)}$

on Grain Size Inferred from Compression Tests

\begin{tabular}{|c|l|c|l|}
\hline $\begin{array}{c}\text { Distance } \\
\text { from end } \\
\text { of Tube 74B } \\
\text { (inches) }\end{array}$ & \multicolumn{1}{|c|}{ Coolant } & $\begin{array}{c}\text { Temperature } \\
\text { of Cooling } \\
\text { Medium } \\
(\mathrm{F})\end{array}$ & $\begin{array}{c}\text { Apparent } \\
\text { Grain Size }\end{array}$ \\
\hline 119 & Still Air & 77 & Coarse \\
122 & Forced Air, 3000 fpm & 77 & Med. Coarse \\
125 & Forced Air, 1500 fpm & 77 & Med. Coarse \\
69 & Forced Air, 3000 fpm & 39 & Med. Coarse \\
72 & Forced Air, 1500 fpm & 43 & Med. Coarse \\
113 & Salt (2) & 970 & Med. Coarse \\
116 & Oil (3) & 77 & Fine \\
\hline
\end{tabular}

(1) Specimens held $10 \mathrm{~min}$. in $1360^{\circ} \mathrm{F}$ salt bath, held $20 \mathrm{sec}$. in air, then cooled as indicated.

(2) Quenched in Houghton 235 salt for 10 min.

(3) Poco No. 2. 


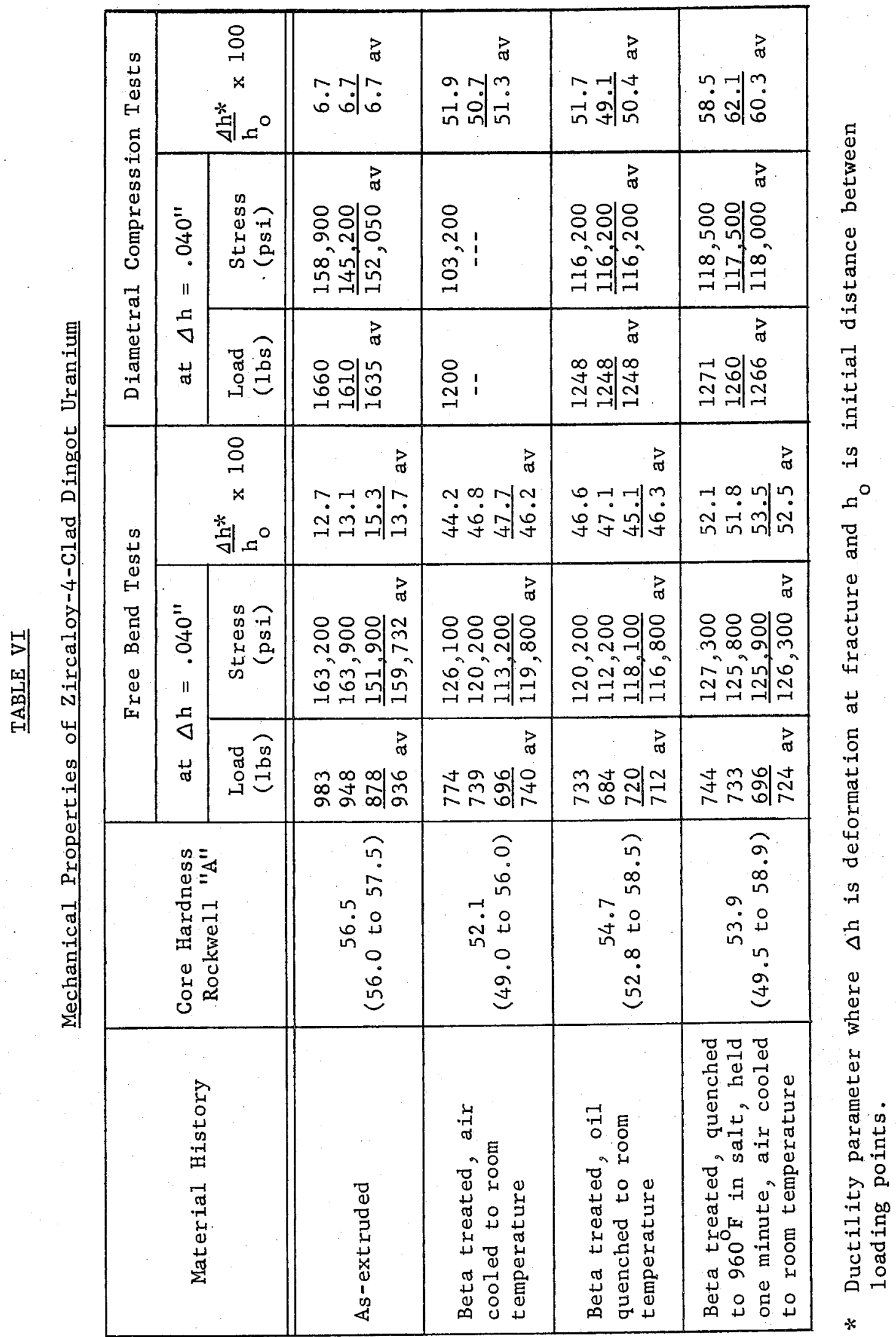




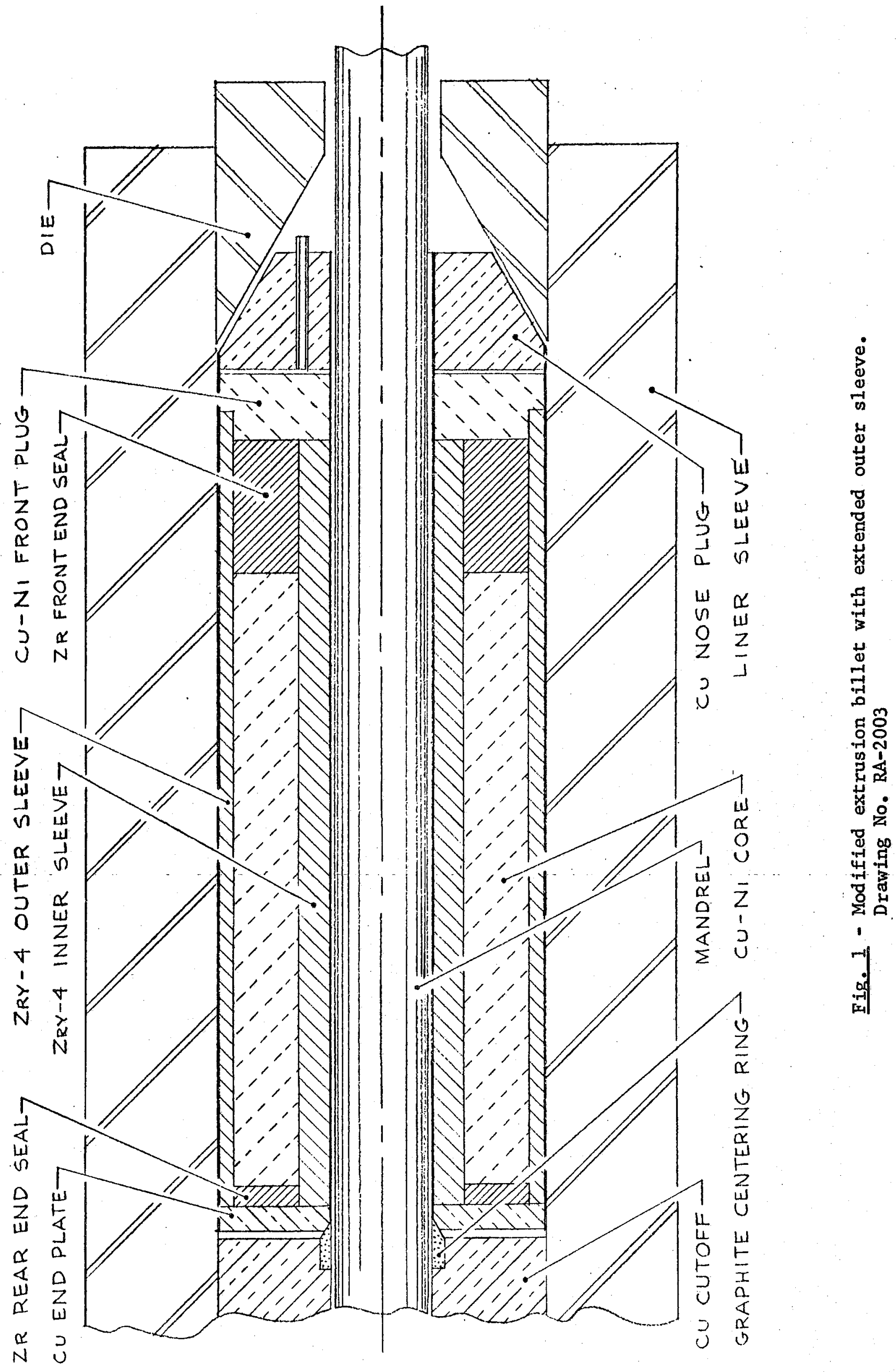




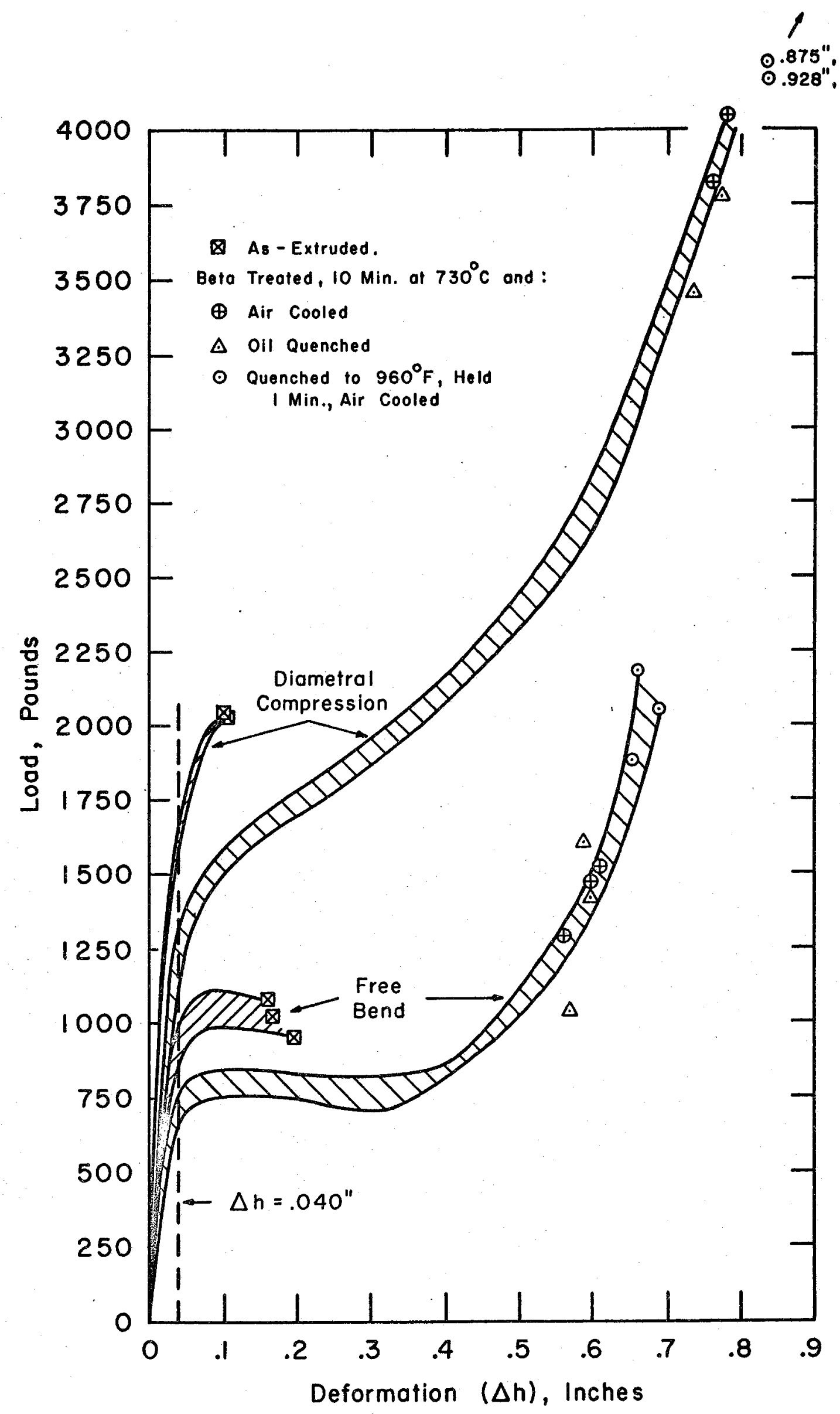

Fig. 2 - Load vs. deformation curves of Zircaloy-4-clad dingot uranium. Drawing No. RA-2025 


\section{Notebook Nos.}

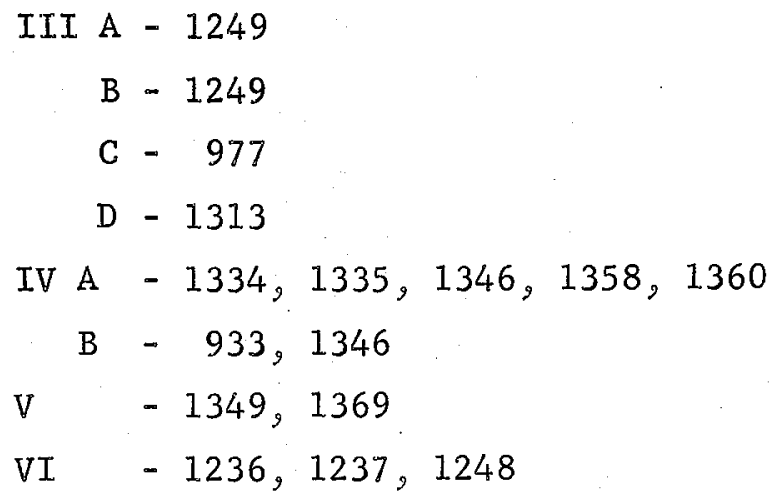

